Elsevier

\title{
The postnatal development of layer VI pyramidal neurons in the cat's striate cortex, as visualized by intracellular Lucifer yellow injections in aldehyde-fixed tissue
}

\author{
J. Lübke and K. Albus \\ Max-Planck-Institut für Biophysikalische Chemie, Abteilung Neurobiologie, Göttingen (F.R.G.)
}

(Accepted 16 August 1988)

Key words: Postnatal development; Layer VI pyramidal neuron; Striate cortex; Lucifer yellow; Intracellular injection; Aldehyde-fixed tissue; Photo-oxidation

\begin{abstract}
The postnatal development of layer VI pyramidal neurons in the cat's striate cortex has been studied by means of intracellular injections of Lucifer yellow in aldehyde-fixed tissue (LYF technique). It is shown that the LYF technique gives results qualitatively and quantitatively similar to results obtained with other techniques (Golgi, marker-injections in viable tissue). Quantitative analysis demonstrated significant increases in soma diameter, number and length of basal dendrites, length of second order apical dendrites and, in particular, in number of spines/unit dendritic length, during the first postnatal month. Maturation of the basal dendritic tree and increase in number of spines continue in the second postnatal month. At later postnatal times soma diameter and number of spines decrease by about $20 \%$. Dendritic varicosities are most frequent during the first postnatal week, and decrease in number steadily from thereon. The late maturation of layer VI pyramidal neurons suggests that these cells might be affected by early peripheral lesions and/or sensory deprivation to which the striate cortex of the cat has been shown to be most susceptible around the end of the first postnatal month.
\end{abstract}

\section{INTRODUCTION}

A wealth of studies has been devoted to physiological changes in visual cortical neurons of monkey and cat following peripheral lesions or sensory deprivation (recent reviews, see refs. 29, 36). In contrast, the dendritic and axonal maturation of these neurons under deprived conditions has received almost no attention with a few notable exceptions ${ }^{5,30,36}$. In the cat's visual cortex normal development has been studied prenatally in pyramidal and other neurons ${ }^{22,33}$, and postnatally in non-pyramidal neurons ${ }^{27,46,47}$. Systematic data on the maturation of pyramidal cells are lacking.

In this report we present data on the postnatal development of layer VI pyramidal neurons in the cat's striate cortex (area 17). Our main goal was to pro- vide a baseline for further studies of normal neuronal maturation and development under sensory deprivation. A second aim was to demonstrate the suitability of intracellular injections of Lucifer yellow (LY) in aldehyde-fixed tissue (LYF method ${ }^{38}$ ) for providing quantitative data of neuronal morphology. For this, the LY-injected neurons were compared with neurons impregnated with the Golgi-method.

\section{MATERIALS AND METHODS}

\section{Animal preparation}

LY injections were performed in 10 cats ranging in age from newborn to adulthood. The following postnatal days (PN) were investigated: 1 (day of birth), 5 , 11 (two kittens), 19, 30, 50 (two kittens) and two adult cats. After deeply anaesthetizing the cats with

Correspondence: J. Lübke, Max-Planck-Institut für Biophysikalische Chemie, Abteilung Neurobiologie, Am Faßberg, 3400 Göttingen, F.R.G. 
sodium pentobarbitone (Nembutal, $60 \mathrm{mg} / \mathrm{kg}$ b. wt.), physiological saline containing heparin (Liquemin, $25.000 \mathrm{I}$.U.) was used to rinse the vascular system. When the washing solution appeared to be clear, the perfusion was continued over 20-45 min with $4 \%$ paraformaldehyde in $0.1 \mathrm{M}$ phosphate buffer (PB) pH 7.4 containing small amounts of sucrose and picrinic acid. The occipital cortex was removed from the brain and a small piece of tissue was blocked with a non-toxic glue (Histoacryl) and, without further embedding, serially cut in a frontal plane at $120 \mu \mathrm{m}$ on a vibratome (Oxford Instruments, U.K.; or Dosaka Instruments, Tokyo, Japan). Pieces of cortex and slices not required for immediate injection were stored in $0.1 \mathrm{M} \mathrm{PB} \mathrm{pH} 7.4$ in a refrigerator. Prior to injection, slices were incubated for $5-10 \mathrm{~min}$ in a $10^{-13} \%$ solution of the DNA-stain 4.6 diamino-2phenyl-indol (DAPI, Sigma). This staining procedure resulted in brightly fluorescent nuclei which provide a clear target for the LY-filled pipette and a basis for determining the layer $\mathrm{VI} /$ white matter border. Alternate slices were mounted on slides and counterstained with either Nissl or cytochromoxidase to identify the cortical layers. For dye injection, slices were carefully mounted with a brush on a slide. The tissue was held down by a Millipore filter with a window cut slightly smaller than the slice. Small pieces of metal were placed on the filter to prevent the slice floating in the injection chamber. Finally, the preparation was placed in a Petri dish containing $0.1 \mathrm{M} \mathrm{PB} \mathrm{pH} 7.4$ at room temperature. This arrangement was attached to the stage of a microscope. Borosilicate filament pipettes (tip diameter $0.5-1 \mu \mathrm{m}$, resistance ranging from $90-250 \mathrm{M} \Omega$ measured in 0.1 $\mathrm{M} \mathrm{PB} \mathrm{pH} \mathrm{7.4)} \mathrm{filled} \mathrm{with} \mathrm{a} \mathrm{3-5 \%} \mathrm{aqueous} \mathrm{solution} \mathrm{of}$ $\mathrm{LY}$ were aimed to neurons at the layer VI/white matter border. After successfully penetrating a neuron through its cell body, or one of its dendrites, dye was iontophoretically injected with a constant negative current of $\leqslant 5 \mathrm{nA}$ for 3-5 min. Dye filling of a cell was judged complete when the fine distal processes also appeared brightly fluorescent. A modified photooxidation protocol ${ }^{21}$ was used to transform the fluorescent dye into a stable Golgi-like reaction product. Slices with LY-filled cells were preincubated for $5-10 \mathrm{~min}$ in $0.1 \mathrm{M} \mathrm{PB} \mathrm{pH} 7.4$ containing $1.5 \mathrm{mg} / \mathrm{ml} \mathrm{di}$ aminobenzidine (DAB) Grade II (Sigma). After 20-30 min of irradiation of the neuron with LY exci- tation wavelength (Zeiss filter combination (BP) 436 $\mathrm{nm}$, (FT) $460 \mathrm{~nm}$ and (LO) $470 \mathrm{~nm}$ ), using the Nikon ELWD $40 \times$ objective, all visible fluorescence from the filled cell had faded and a homogeneous brown Golgi-like reaction product had been formed. Excess DAB was washed out in several rinses with $\mathrm{PB}$, sections were mounted and dried to coverslip. To enhance the staining contrast, slices were briefly stained in a $1 \%$ solution of osmium tetroxide in $0.1 \mathrm{M}$ PB pH 7.4 for 2-3 min. This was followed by dehydration in an ascending series of ethanol, clearing in xylene and embedding in resin. Due to the highly osmiophilic nature of the DAB reaction product, photo-oxidized neurons appeared black with only moderately increased background staining. Cells were reconstructed with the aid of a camera lucida at a magnification of $800 \times$. These drawings formed the basis for the quantitative analysis. A more detailed account of the LYF-method has appeared elsewhere ${ }^{4}$.

Four kittens (at PN 3, 11, 19, 55) were perfused with a Golgi solution, containing $3.5 \%$ potassium dichromate, $2.5 \%$ glutaraldehyde, and $1 \%$ chloral hydrate $^{26}$. Immediately after perfusion the occipital cortex was dissected from each hemisphere and cut in a frontal plane in 4 or 5 blocks. After immersion between 3 and 7 days in the Golgi-solution the blocks were transferred to $0.75 \%$ silver nitrate, for $48 \mathrm{~h}$. Thereafter blocks were cut with a razor blade into sections approximately $200-300 \mu \mathrm{m}$ thick, and finally dehydrated and mounted in soft Epon under coverslips.

\section{RESULTS}

From a total of 250 neurons which were dye-filled with LY in 10 cats, 150 pyramidal neurons were selected for further qualitative and quantitative evaluation. The LYF-technique reveals neurons indistinguishable from Golgi-stained material. Dendrites are stained to the very tip (Fig. 1A), and fine details as growth-cones (Fig. 1B), varicosities (Fig. 1E) and dendritic spines (Fig. 1B,D) are easily recognized in the LYF-material. Occasionally hair-like processes or spine-like protrusions (Fig. 1C) are detected on neuronal somata, especially in younger kittens. Proximal portions of axons are well-filled, so that a decision could be made whether or a not a neuron sends of projection into the underlying white matter. Since 

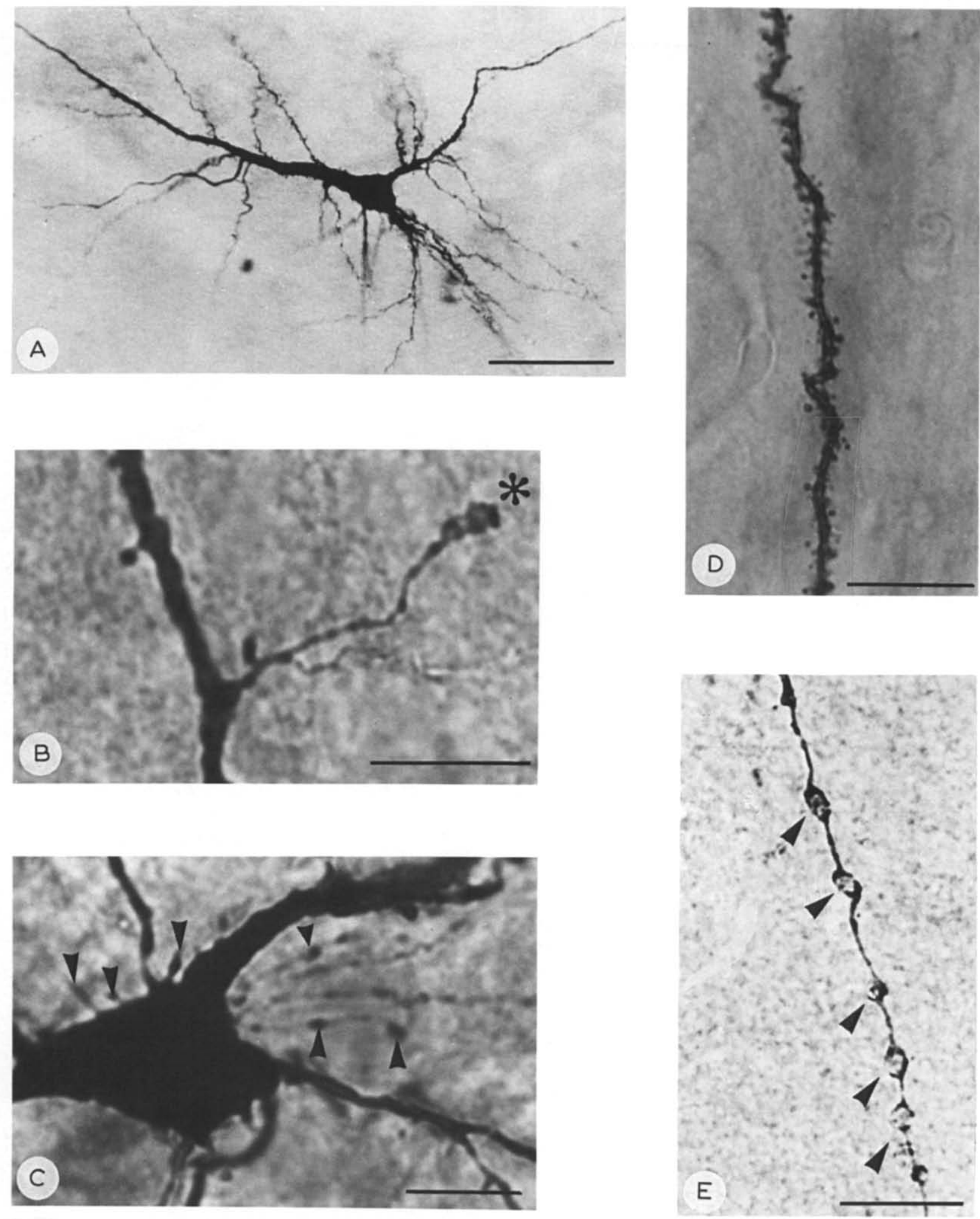

Fig. 1. Photomicrographs of LY-stained layer VI pyramidal neurons in the cat's striate cortex after photo-oxidation. A: low magnification of a horizontally oriented pyramidal cell in sublamina VIb in the lateral part of area 17. B: high power magnification of an apical dendrite (PN 5) with a second order dendrite branching from it, terminating in a growth-cone like structure (asterisk). C: high-power magnification of spine-like protusions and hair-like processes (arrowheads) at the soma region of a 5-day-old kitten. D: high power magnification of an apical dendrite (PN 50), which clearly reveals the morphology and distribution of spines along the apical shaft. E: basal dendrite of a layer VIa pyramidal neuron (PN 5) with numerous large varicosities (arrowheads). The granular background staining results from the brief osmification procedure. Bar in $\mathrm{A}=50 \mu \mathrm{m}$, in $\mathrm{B}-\mathrm{D}=10 \mu \mathrm{m}$, in $\mathrm{E}=20 \mu \mathrm{m}$. 


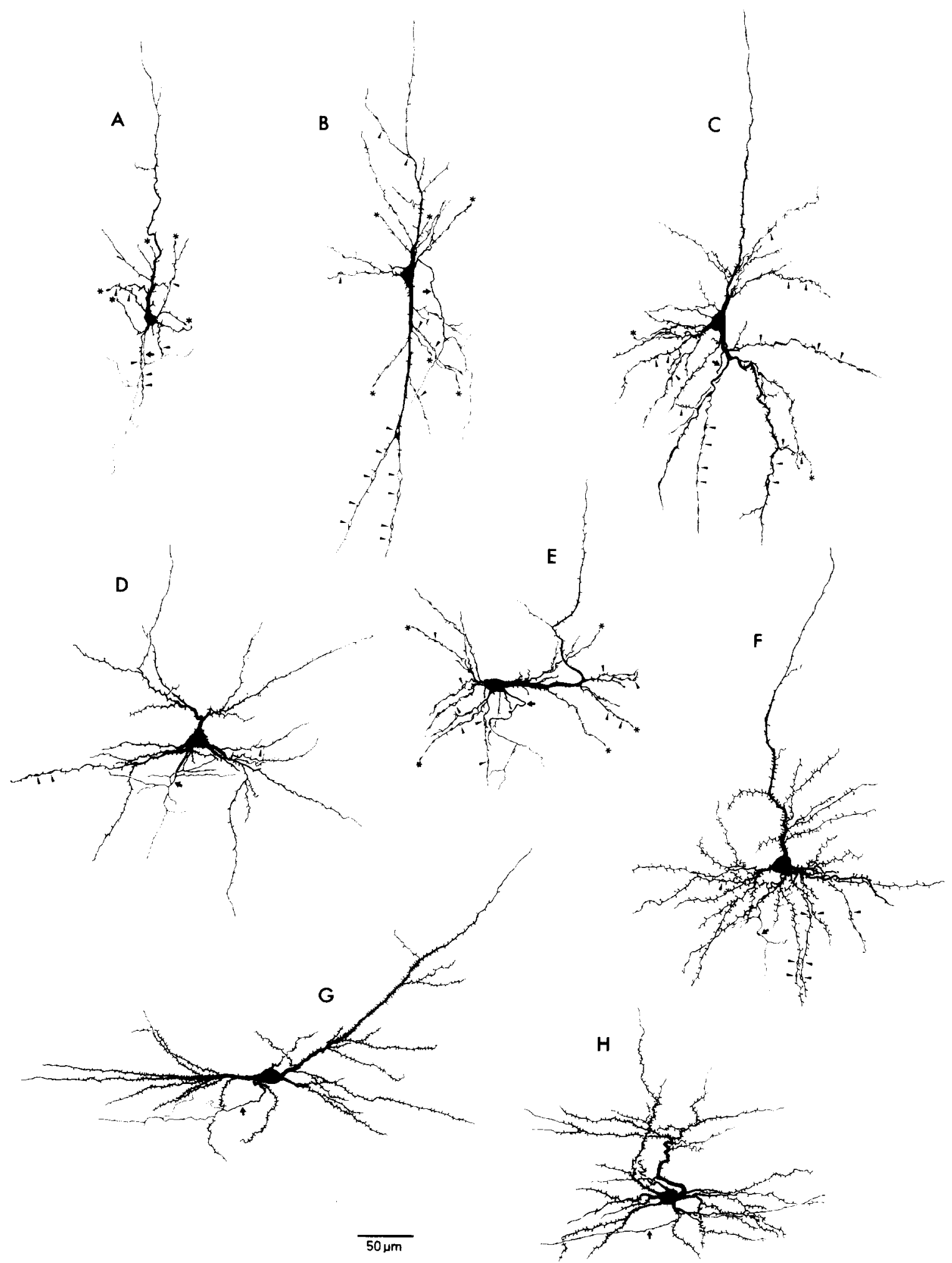

Fig. 2. Camera lucida drawings of layer VI pyramidal neurons in the cat's striate cortex. A: vertically oriented pyramidal neuron (PN 1) located at the apex in sublamina VIb of area 17. B: pyramidal neuron with a fusiform morphology (PN 5). C: medium-sized pyramidal neuron (PN 11) with an elongated main basal process. D: pyramidal neuron (PN 19) with a 'triangular' shaped cell body. E: horizontal pyramidal neuron (PN 30) from the sulcal region. F: medium sized pyramidal neuron at PN 30 . G: horizontally oriented pyramidal neuron (PN 50). H: pyramidal neuron found in sublamina VIb at the sulcal region of area 17. Due to the cortical folding the apical dendrite follows a sinous course to the pial surface with a horizontal terminal tuft in deeper layer IV. Axons are indicated by arrows, dendritic varicosities by arrowheads and dendritic growth-cones by asterisks. 
more distal portions and terminal parts of axons were only occasionally filled the quantitative analysis will be restricted to soma and dendritic pattern.

Most varieties of pyramidal neurons as reported in previous Golgi-studies to reside in layer VI of the cat's visual cortex ${ }^{9.40}$ were also detected in the LYFmaterial, at all postnatal ages. Of the sample $90 \%$ are medium-sized pyramidal neurons which assume fusiform shapes near the lateral gyrus (Fig. 2B), a more triangular shape near the bottom of the suprasplenial sulcus (Fig. 2D) and 'true' pyramidal shapes in the medial bank of the lateral gyrus (Fig. 2F). Some neurons with one prominent basal dendrite resemble neurons projecting to the claustrum ${ }^{19}$ (Fig. $2 \mathrm{C}$ ). About $10 \%$ of our sample includes 'improperly' oriented pyramidal neurons ${ }^{45}$, among them horizontally oriented (Fig. 2E,G) and inverted pyramidal cells. Most of these neurons are located close to the bottom of the suprasplenial sulcus, in sublayer VIb. Some horizontal neurons have a long apical dendrite running parallel to the layer VI/white matter border, and a thick basal dendrite ascending obliquely to layer IV (Fig. 2G). In other horizontally oriented neurons the apical dendrite runs straight for 200-500 $\mu \mathrm{m}$, but then turns into a vertical direction and leaves layer VI (Fig. 2E). The latter cell type has also been classified as 'altered' pyramidal neurons ${ }^{40}$. In many horizontally oriented pyramidal neurons the axon originates from proximal parts of the apical shaft. The basal dendrites of mature layer VI neurons distribute mainly in layer VI and V, and are much more numerous than apical dendrites. The primary apical dendrite accompanied by a few second order dendrites usually extends into layer IV; apical tufts as typically seen at layer II/III and layer V pyramidal cells were rarely found in our material (Fig. $2 \mathrm{H}$ ). The sparsity of distal parts of apical dendrites of layer VI pyramidal neurons is evident also in HRP-filled material from intact visual cortex ${ }^{12,13,25}$, and in LY-filled neurons from in vitro slice preparations ${ }^{19}$. Apical dendrites reaching layer $I^{19,40}$ were not seen in the LYF-material (see below).

Neurons at PN 1 and PN 5 have in common short and sparsely branching basal dendrites, short secondary apical dendrites arising from a relatively long main apical stem, and small somata (Fig. 2A,B). The density of dendritic spines is extremely low; the few second and third order dendrites are covered with varicosities and bear growth-cones at their tips (Figs. 1B, 2A-E). As can be seen in Fig. 2 the number and length of basal dendrites, the spine density as well as the soma diameter dramatically increase from birth to adulthood. In contrast, growth-cones and varicosities decrease in their frequency of occurrence and are

\section{TABLE I}

\section{Changes of layer VI pyramidal cell morphology during postnatal development}

Mean soma size was estimated from the mean length of the maximum and minimum soma diameter of each cell measured with an ocular micrometer. Total dendritic length, from intact dendrites as well as from dendrites leaving the plane of section, was measured with the aid of a planimeter. The means \pm S.D. for neurons sampled at each age are shown. Interindividual differences at PN 19, PN 50 , and in the adult, were not seen.

\begin{tabular}{|c|c|c|c|c|c|c|c|}
\hline & PN 1 & PN 5 & PN11 & $P N 19$ & PN30 & PN 50 & Adult \\
\hline Soma size $(\mu \mathrm{m})$ & $12.14 \pm 0.94$ & $14.75 \pm 1.94$ & $15.73 \pm 1.76$ & $18.11 \pm 1.67$ & $20.10 \pm 1.49$ & $18.24 \pm 1.14$ & $17.69 \pm 0.83$ \\
\hline $\begin{array}{l}\text { Spines } / 100 \mu \mathrm{m} \\
\text { Varicosities/ }\end{array}$ & $3.42 \pm 2.59$ & $4.51 \pm 1.88$ & $6.56 \pm 2.50$ & $12.79 \pm 2.56$ & $24.42 \pm 5.90$ & $30.91 \pm 8.74$ & $24.39 \pm 3.18$ \\
\hline $\begin{array}{l}100 \mu \mathrm{m} \\
\text { Mean length of }\end{array}$ & $2.38 \pm 1.30$ & $3.49 \pm 1.15$ & $2.66 \pm 1.21$ & $1.26 \pm 0.89$ & $0.27 \pm 0.24$ & $0.15 \pm 0.17$ & $0.02 \pm 0.05$ \\
\hline $\begin{array}{l}\text { apical dendrites } \\
\text { Mean length of }\end{array}$ & $456.60 \pm 137.60$ & $610.72 \pm 169.13$ & $687.76 \pm 190.38$ & $758.18 \pm 161.31$ & $650.26 \pm 114.81$ & $744.26 \pm 215.28$ & $605.32 \pm 131.73$ \\
\hline $\begin{array}{l}\text { basal dendrites } \\
\text { Number of sec. }\end{array}$ & $491.96 \pm 204.55$ & $604.43 \pm 159.16$ & $880.87 \pm 259.29$ & $1086.89 \pm 254.05$ & $1219.22 \pm 209.53$ & $1277.15 \pm 300.82$ & $1291.99 \pm 181.80$ \\
\hline $\begin{array}{l}\text { apical dendrites } \\
\text { Numter of prim. }\end{array}$ & $5.71 \pm 2.16$ & $8.07 \pm 2.34$ & $7.83 \pm 2.59$ & $7.47 \pm 2.30$ & $6.60 \pm 1.96$ & $7.13 \pm 2.26$ & $6.54 \pm 1.96$ \\
\hline $\begin{array}{l}\text { basal dendrites } \\
\text { Number of neurons } \\
\text { (number of } \\
\text { animals) }\end{array}$ & $5.14 \pm 1.51$ & $6.93 \pm 2.02$ & $6.47 \pm 1.65$ & $9.20 \pm 2.91$ & $9.53 \pm 2.53$ & $9.60 \pm 1.45$ & $9.35 \pm 1.87$ \\
\hline
\end{tabular}


rarely seen at later postnatal periods. The quantitative analysis of the LYF-material is presented in Table I. The various parameters evaluated increase in size after birth and reach a maximum at different postnatal ages; from thereon, either no further change, or even a decrease is observed. The mean soma diameter increases by $65 \%$ between PN 1 and PN 30, and from thereon decreases by $23 \%$ ( $P<$ $0.01)$. There is a nearly 10 -fold increase in the number of spines from birth to PN 50, and subsequently a slight but significant reduction by $19 \%(P<0.01)$ to adulthood. The number of primary basal dendrites and the total length of basal dendrites increase until PN 19, and PN 30 respectively, and then remain constant to adulthood. The number of secondary apical dendrites and the total length of apical dendrites increase until PN 5, and PN 19 respectively, and then, after some variations, decrease. A time course somewhat different from that described so far was seen for the dendritic varicosities, which have been recognized as a typical feature of developing dendrites ${ }^{18}$. Varicosities are frequent at birth, reach a maximum at PN 5 and from thereon substantially decrease in number to adulthood.

For the sake of comparison with the LYF-material, 80 neurons which appeared to be completely stained were selected from the Golgi material. The quantitative analysis of these neurons concerned mean number of spines/neuron and mean number of varicosities/neuron and the results are summarized in Table II. Interestingly, the total number of spines is nearly the same until PN 11; at PN 19 and around PN 50 the number of spines is higher in Golgi-stained neurons (by $28 \%$, and $14 \%$ respectively). This difference is most probably due to the fact that the Golgi-material contained neurons with apical dendrites and dendritic arborizations reaching layer II and I; such neurons were not found in the LYF-material. The $250-300-\mu \mathrm{m}$ thick Golgi sections thus contain more dendritic processes, in particular at sites distant from the cell body, than the LYF-material sectioned at 120 $\mu \mathrm{m}$ (see also Discussion). The number of varicosities/ neuron determined in the Golgi-stained neurons was smaller than in the LYF-material, and no reasonable explanation for this discrepancy can be offered at the moment. Nevertheless, the changes revealed with the LYF-technique, namely a slight initial increase followed by a significant decrease at later postnatal times were also seen in the Golgi-material.

For a further analysis of postnatal changes we counted the number of intersections of dendrites with a series of concentric circles evenly spaced at $20 \mu \mathrm{m}$ intervals centered around the cell body and the number of dendritic branchings found between succesive circles $^{1,19}$. The results are summarized in Fig. 3. The number of intersections of basal dendrites $30 \mu \mathrm{m}$ $150 \mu \mathrm{m}$ distant from the soma increases $2-3$-fold between PN 1 and PN 11, and a further increase of $10 \%$ to $25 \%$ is noted until PN $30,30-90 \mu \mathrm{m}$ distant from the soma. The maximal number of intersections is located $30 \mu \mathrm{m}$ distant from the soma at PN 1 and shifts to $50-70 \mu \mathrm{m}$ at later postnatal ages. A 2-4-fold increase is seen for the number of branchings of basal dendrites measured between successive circles. This increase occurs $30-70 \mu \mathrm{m}$ distant from the soma between PN 1 and PN 11 , and $30 \mu \mathrm{m}$ distant from the soma between PN 11 and PN 30. The increase in dendritic branching is the main reason for the increase in

\section{TABLE II}

\section{Changes in the total number of spines/neuron and varicosities/neuron during postnatal development}

The means \pm S.D. at each age are shown. LY, Lucifer yellow filled neurons, Golgi, stained with the Golgi technique ${ }^{23}$. Number of neurons stained with the Golgi technique are given in brackets at PN 11 and PN 19. The neurons stained with LY are the same as shown in Table I.

\begin{tabular}{llllllll}
\hline & $P N 1$ & $P N 3$ & $P N 5$ & $P N 11$ & $P N 19$ & $P N 50$ & $P N 55$ \\
\hline Spines/neuron & & & & & & & \\
$\quad$ LY & $30.95 \pm 11.45$ & - & $51.50 \pm 11.70$ & $102.28 \pm 49.00$ & $235.20 \pm 47.37$ & $567.20 \pm 127.16$ & - \\
$\quad$ Golgi & - & $43.60 \pm 12.73$ & - & $106.00 \pm 69.20$ & $303.45 \pm 168.85$ & - & $648.45 \pm 133.86$ \\
$\quad$ Varicosities/neuron & & & & & & & \\
$\quad$ LY & $20.65 \pm 8.97$ & - & $41.15 \pm 9.16$ & $39.62 \pm 14.07$ & $24.00 \pm 14.43$ & $2.80 \pm 2.91$ & - \\
$\quad$ Golgi & - & $19.60 \pm 8.43$ & - & $23.20 \pm 12.40$ & $18.43 \pm 10.47$ & - & $1.55 \pm 1.43$ \\
Number of neurons & 20 & 20 & 20 & $40(20)$ & $15(20)$ & 20 & 20 \\
\hline
\end{tabular}



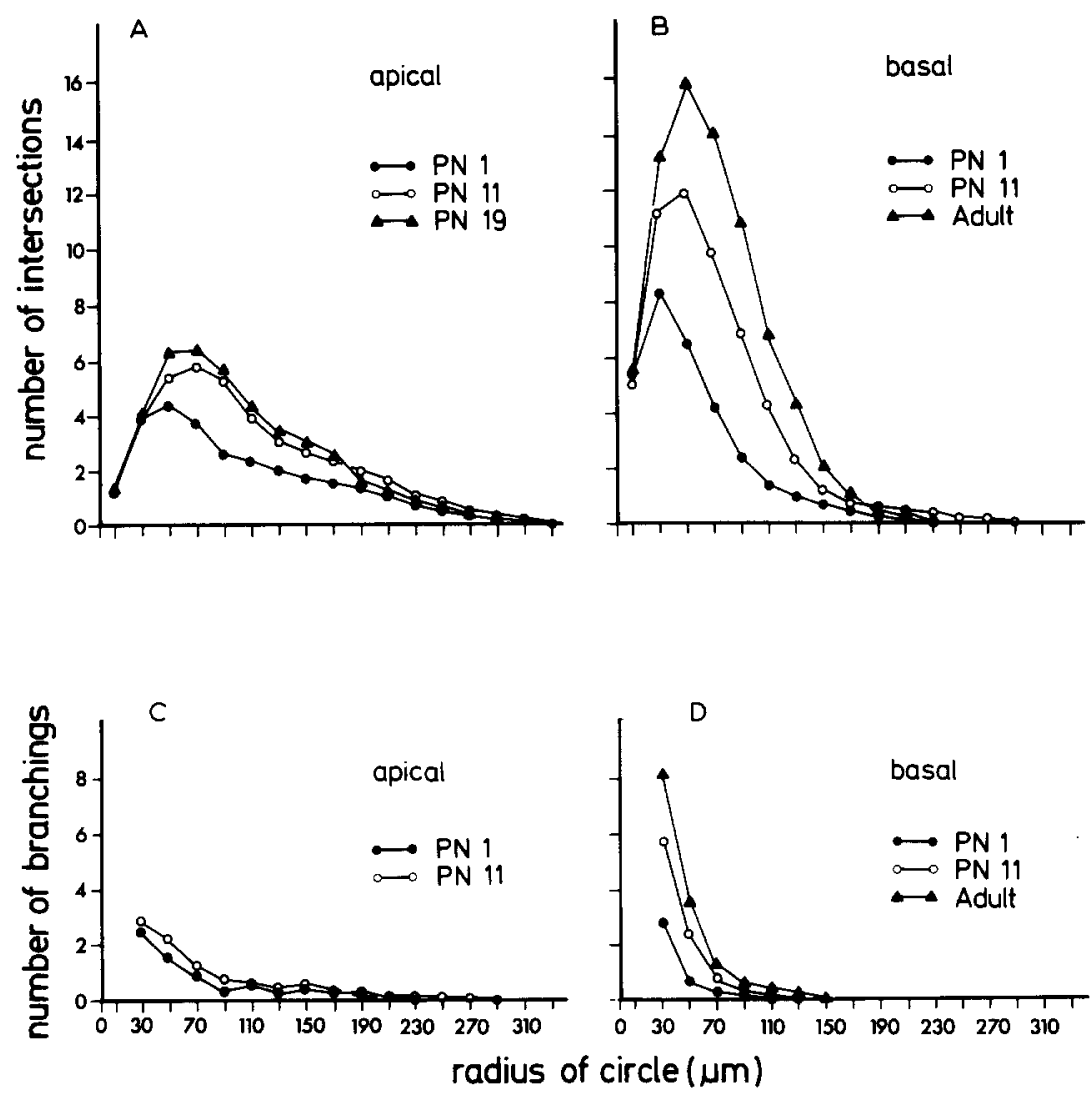

Fig. 3. The number of intersections of apical (A) and basal (B) dendrites with a series of concentric circles, evenly spaced at $20 \mu \mathrm{m}$ around the cell body, and the number of branchings of apical (C) and basal (D) dendrites, between successive circles, is given. Number of cells, see Table I. The number of intersections and branchings of basal dendrites at PN 30 and PN 50 are not significantly different from the corresponding adult values shown in this figure. For stages not shown in this figure see text.

the number of intersections at distances up to $50-70$ $\mu \mathrm{m}$ from the soma. Further distant from the soma, however, an increase in both branching and length of individual dendrites contributes to the increase in size of the basal dendritic tree. Increase in length is also demonstrated by the fact that the proportion of the second and third order basal dendrites $20-40 \mu \mathrm{m}$ long decreases from $81 \%$ at PN 1 to $35 \%$ at PN 11 , and $31 \%$ at PN 19 ; on the other hand the proportion of dendrites $60-80 \mu \mathrm{m}$ long increases from zero at PN 1 to $16 \%$ at PN 11, and $23 \%$ at PN 19.

The number of intersections of the apical dendrite 50-130 $\mu \mathrm{m}$ distant from the soma increases, from PN 1 to PN 11, and remains constant thereafter. A small, unsignificant increase was noted $130-190 \mu \mathrm{m}$ away from the soma. Since the number of branchings of the apical dendrites did not change, the increase in intersections must be caused solely by an increase in length of individual secondary dendritic branches.

\section{DISCUSSION}

The types of layer VI pyramidal neurons seen in the LYF-material resemble those described in previous studies, using the Golgi technique ${ }^{6,9,40}$, or intracellular injection of marker substances in in vivo tissue $^{12.19}$. The most frequently occurring type were medium-sized pyramidal neurons ${ }^{40}$ which assumed fusiform morphology in convex parts of the lateral gyrus and a more triangular form near, or within, the suprasplenial sulcus. We have also filled 'altered' pyramidal neurons ${ }^{40}$, 'improperly' oriented cells ${ }^{45}$ as well as horizontally oriented pyramidal neurons with an ascending basal dendrite. Almost all neurons had an axon or an axon collateral descending into adjacent white matter. This observation does not prove, however, that these neurons are projection neurons since some intracortically projecting pyramidal neurons have also been shown to possess an axon pro- 
jecting to and ending within the white matter ${ }^{19}$.

The extent and complexity of the basal dendritic field of mature layer VI pyramidal neurons, as seen in the LYF-material, is nearly the same as that reported for an in vitro slice preparation ${ }^{19}$. In the latter study, the maximum in the number of intersections with a series of concentric circles was found at about $60 \mu \mathrm{m}$ from the soma and numbered 14 for the LGN projection neurons, and about 19 for neurons projecting to the claustrum; in the LYF-material a maximum number of sixteen intersections was counted 50 $\mu \mathrm{m}$ from the soma. Basal dendrites extended up to $270 \mu \mathrm{m}$ in the LYF-material, and up to $240 \mu \mathrm{m}$ (LGN projection neurons), and $400 \mu \mathrm{m}$ respectively (claustrum projection neurons) in the in vitro slice preparation. The maximum number of intersections (about 6) of apical dendrites in the concentric ring analysis is the same for both techniques. A difference is apparent, however, in the extent of the apical dendritic field; in the in vitro slice preparation, on average two intersections were counted $400 \mu \mathrm{m}$ distant from the soma, whereas in the LYF-material the average number of intersections $250 \mu \mathrm{m}$ distant from the soma is one and drops to zero at $310 \mu \mathrm{m}$. This difference can most readily be explained by section thickness of the LYF-material, which was $400 \mu \mathrm{m}$ in the in vitro slice study and $120 \mu \mathrm{m}$ in the LYF-study. The limited section thickness of the LYF-material might also explain why we did not fill a cell with an apical dendrite reaching layer $\mathrm{II}$ or $\mathrm{I}$, as typically seen for neurons projecting to the claustrum ${ }^{19}$. A few neurons were found, however, in which the main apical dendrite was cut off within layer IV. Loss of apical dendrites of deep layer pyramidal neurons in superfical layers has also been reported in Golgi-material sectioned at $100 \mu \mathrm{m}^{17}$.

The changes in morphological parameters defined in our study proceed at different rates. Firstly, the number of dendritic varicosities peaks much earlier (about PN 5) than all other parameters; secondly, growth of dendrites seems to continue for longer times postnatally than dendritic branching. Dendritic varicosities occur most frequently between PN 1 and PN 19; at PN 30 they have declined by a factor of more than 10 when compared to their maximal density at PN 5 (see Table I). It is interesting that the highest density of dendritic varicosities (between PN 1 and PN 11) is correlated in time with a steep in- crease in mean length of basal dendrites (see Table I) and basal dendritic branching, as well as with an increase in spine density (see Table I). One may speculate that dendritic varicosities contain material, such as microfilaments, that promotes the growth of dendrites rather than dendritic spines. This suggestion receives some support from the observation that the primary apical dendrite never contained a dendritic varicosity, although the spine density increased considerably; in addition, spine density increases significantly between PN 30 and PN 50 - during this time the density of varicosities has decreased by one order of magnitude - and nearly no further significant growth of basal dendrites could be observed.

The time-lag between dendritic branching and the increase in dendritic length is most clearly seen for the apical dendrites. Here the increase in the number of intersections between PN 1 and PN 11, seen in the concentric ring analysis, is almost exclusively due to an increase in the length of individual dendrites since there is no clear increase in the number of branches during that time. Basal dendrites stop branching from PN $11 \mathrm{on}$, at distances of $50 \mu \mathrm{m}$ or more from the soma. Since, at later postnatal times, $80 \%$ of second and third order dendrites are shorter than $60 \mu \mathrm{m}$ and about one third shorter than $40 \mu \mathrm{m}$, the increase in the number of intersections after PN 11 should be accountable by the increase in dendritic length, rather than by the increase in dendritic branching.

Our findings agree with earlier studies on the postnatal dendritic maturation of pyramidal neurons in the striate cortex of the human ${ }^{1.6}$, the macaque monkey (layer III and upper VI) ${ }^{2.20}$, rabbit (layer V) ${ }^{24}$ and rat (layer II/LII and $V)^{17.18 .28 .32}$, which report a significant increase in length and number of basal dendrites. Differential phasing of morphological features, as seen in our study, has recently been reported for layer $\mathrm{V}$ pyramidal neurons in the rat's neocortex ${ }^{32}$. In this case, formation of primary basal dendrites stops early (around PN 10). Subsequently, dendritic branching reaches a plateau around PN 20, whereas the length of basal dendrites continues to increase to later postnatal dates and even to adulthood. The decrease in complexity of dendritic trees, occurring during later postnatal periods in the monke ${ }^{2}$ has not been seen in our material.

The significant increase in soma diameter has also been reported for layer $\mathrm{V}$ pyramidal neurons of the 
cat's striate cortex ${ }^{41}$ and for layer II/III and layer V pyramidal cells in species other than the cat $^{20,24,28}$. The slight reduction in soma size which was observed at later postnatal times in the cat, was also reported in the monkey ${ }^{20}$.

The enormous increase in spine density after birth, occurring at both apical and basal dendrites of layer VI pyramidal neurons is a common feature of the postnatal maturation of all pyramidal neurons studied so $\mathrm{far}^{2,6,7,16-18,20,23,24,28,30,49}$. The increase in the number of spines correlates well with the increase in the density of axo-spinous, asymmetric synapses, the most frequent type of synapses in cat's visual cortex, as seen in an EM study of cat's striate cortex ${ }^{48}$. Since this study demonstrated a further increase in synaptic density between PN 40 and PN 70, the maximum spine density might be somewhat higher than found in our study. A decrease in the density of spines, after the second postnatal month, has also been observed in a Golgi study of the striate cortex of rhesus mon$\mathrm{key}^{24}$. The decrease in spine density of layer VI pyramidal neurons should lead to a decrease in synaptic density in layer VI (and this has been reported in EM studies $^{34,48}$ ), and since apical dendrites of layer VI pyramidal neurons may span the full thickness of the cortex, the decrease in spine density of these cells

\section{REFERENCES}

1 Becker, E.L., Armstrong, D.L., Chan, F. and Wood, M.M., Dendritic development in human occipital cortical neurons, Dev. Brain Res., 13 (1984) 117-124.

2 Boothe, R.G., Greenough, W.T., Lund, J.S. and Wrege, $\mathrm{K}$., A quantitative investigation of spine and dendritic development of neurons in the visual area 17 of Macaca nemestrina monkeys, J. Comp. Neurol., 186 (1979) 473-490.

3 Borges, S. and Berry, M., Preferential orientation of stellate dendrites in the visual cortex of dark-reared rat, Brain Res., 112 (1976) 141-147.

4 Buhl, E.H. and Lübke, J., Intracellular Lucifer yellow injections in fixed brain slices combined with retrograde tracing, light and electron microscopy, Neuroscience, in press.

5 Coleman, P.D. and Riesen, A.H., Environmertal effects on cortical dendritic fields. I. Rearing in the dark, J. Anat., 102 (1968) 363-374.

6 Conel, J.L., Histologic development of the cerebral cortex, Biol. Ment. Health Disease, 27 (1952) 1-8.

7 Cragg, B.G., The development of synapses in the kitten visual cortex during visual deprivation, Exp. Neurol., 46 (1975) 445-451

8 Eayrs, J.T., The cerebral cortex of normal and hypothyroid rats, Acta Anat., 25 (1955) 160-183.

9 Ferrer, I., Fabregues, I. and Condom, E., A Golgi study of the sixth layer of the cerebral cortex. II. The gyrencephalic might contribute to the decrease of synaptic density in other layers of the cortex as well ${ }^{34,48}$.

Our data show that the maturation of layer VI pyramidal cells in the cat's striate cortex continues during the critical period which peaks between PN 30 and 40 (ref. 31). Besides altering thalamic input ${ }^{15,36}$ peripheral lesions and sensory deprivation might also therefore affect intracortical neuronal circuits in which layer VI pyramidal neurons participate ${ }^{25}$. A retardation in the maturation of axons and dendritic spines, as well as reorientation of dendrites in immature visual and somatosensory cortex, have been reported following early manipulations of peripheral input $^{3,5,8,10,11,14,30,32,35,37,39,42-44}$. In fact, binocular occlusion has been shown to delay the maturation of asymmetric axo-dendritic synapses in the deeper layer of cat's striate cortex ${ }^{29,48}$.

\section{ACKNOWLEDGEMENTS}

We are grateful to C. Sanides-Buchholtz and P. Wahle for providing us with the Golgi-material. This work was supported by the Deutsche Forschungsgemeinschaft (Schwerpunkt 'Dynamik und Stabilisierung neuronaler Strukturen').

brain of Carnivora, Artiodactyla and Primates, J. Anat., 146 (1986) pp. 87-104.

10 Fifkova, E., The effect of unilateral deprivation on visual centers in rats, J. Comp. Neurol., 140 (1970) 431-438.

11 Freire. M., Effects of dark rearing on dendritic spines in layer IV of the mouse visual cortex. A quantitative electron microscopical study, J. Anat., 126 (1978) 193-201.

12 Gilbert, C.D. and Wiesel, T.N., Morphology and intracortical projections of functionally characterised neurones in the cat visual cortex, Nature (Lond.), 28 (1979) 120-125.

13 Gilbert, C.D. and Wiesel, T.N., Clustered intrinsic connections in cat visual cortex, J. Neurosci., 3 (1983) 1116-1133.

14 Harris, R.M. and Woolsey, T.A., Morphology of Golgi-impregnated neurons in mouse cortical barrels following vibrissae damage at different post-natal ages, Brain Res., 161 (1979) 143-149.

15 Hubel, D.H., Wiesel, T.N. and Le Vay, S., Plasticity of ocular dominance columns in monkey striate cortex, Phil. Trans. R. Soc. Lond. Ser. B, 278 (1977) 377-409.

16 Huttenlocher, P.R., De Courten, C., Garey, L.J. and Van der Loos, H., Synaptogenesis in human visual cortex - evidence for synapse elimination during normal development, Neurosci. Lett., 33 (1982) 247-252.

17 Juraska, J.M., The development of pyramidal neurons after eye opening in the visual cortex of hooded rats: a quantitative study, J. Comp. Neurol., 212 (1982) 208-213. 
18 Juraska, J.M. and Fifkova, E., A Golgi study of the early postnatal development of the visual cortex of the hooded rat, J. Comp. Neurol., 183 (1979) 247-256.

$19 \mathrm{Katz}, \mathrm{B}$., Local circuitry of identified projection neurons in cat visual cortex brain slices, J. Neurosci., 7 (1987) $1223-1249$.

20 Lund, J.S., Boothe, R.G. and Lund, R.D., Development of neurons in the visual cortex (area 17) of the monkey ( $\mathrm{Ma}$ caca nemestrina): a Golgi study from fetal day 127 to postnatal maturity, J. Comp. Neurol., 176 (1977) 149-188.

21 Maranto, A.R., Neuronal mapping: a photooxidation reaction makes Lucifer yellow useful for electron microscopy, Science, 217 (1982) 953-955.

22 Marin-Padilla, M., Prenatal ontogenetic history of the neocortex of the cat. A Golgi study. II. Developmental differences and their significances, Z. Anat. Entwickl.-Gesch.. 136 (1972) 125-142.

23 Mates, S.L. and Lund, J.S., Spine formation and maturation of type 1 synapses on spiny stellate neurons in primate visual cortex, J. Comp. Neurol., 221 (1983) 91-97.

24 Mathers, L.H., Postnatal dendritic development in the rabbit visual cortex, Brain Res., 168 (1979) 21-29.

25 McGuire, B.A., Hornung, J.P., Gilbert, C.D. and Wiesel, T.N., Patterns of synaptic input to layer 4 of cat striate cortex, J. Neurosci., 4 (1984) 3021-3033.

26 Meyer, G., Axonal patterns and topography of short-axon neurons in visual areas 17,18 and 19 of the cat, J. Comp. Neurol., 220 (1983) 405-438.

27 Meyer, G. and Ferres-Torres, R., Postnatal maturation of non-pyramidal neurones in the visual cortex of the cat, $J$. Comp. Neurol., 228 (1984) 226-244.

28 Miller, M. . Maturation of the rat visual cortex. I. A quantitative study of Golgi-impregnated pyramidal neurons, $J$. Neurocytol., 10 (1981) 859-878.

29 Mitchell, D.E. and Timney, B., Postnatal development of function in the mammalian visual system. In D. Smith (Ed.), The Handbook of Physiology in the Nervous System, Vol. 3, Part I, American Physiological Society, Bethesda. 1984, pp. 507-555.

30 Neal, J.W., Winfield, D.A. and Powell, T.P.S., The effect of visual deprivation upon the basal dendrites of Meynert cells in the striate cortex of the monkey, Proc. $R$. Soc. Lond. Ser. B, 225 (1985) 411-423.

31 Olson, C.R. and Freeman, R.D., Profile of the sensitive period for monocular deprivation in kittens, Exp. Brain Res., 39 (1980) 17-22.

32 Petit, T.L., LeBoutillier, J.C., Gregorio, A. and Libstug, $\mathrm{H}$., The pattern of dendritic development in the cerebral cortex of the rat, Dev. Brain Res., 41 (1988) 209-219.

33 Ramon Y Cajal, S., Histologie du Système Nerveux de l'Homme et les Vertébrés, Tome I., II., Maloine, Paris. 1911.

34 Rakic, P., Bourgeois, J.-P., Eckenhoff, M.F., Zeceviv, N. and Goldman-Rakic, P.S., Concurrent overproduction of synapses in diverse regions of the primate cerebral cortex,
Science, 232 (1986) 232-235.

35 Ruiz-Marcos, A. and Valverde, F., Dynamic architecture of the visual cortex, Brain Res., 19 (1970) 25-39.

36 Sherman, S.M. and Spear, P.D., Organization of visual pathways in normal and visually deprived cats, Physiol. Rev., 62 (1982) 738-855.

37 Steffen, H. and Van der Loos, H., Early lesions of mouse vibrissal follicles: their influence on dendrite orientation in the cortical barrelfield, Exp. Brain Res., 40 (1980) 419-431.

38 Tauchi, M. and Masland, R.H., The shape and arrangement of the cholinergic neurons in the rabbit retina, Proc. R. Soc. Lond. Ser. B, 223 (1984) 101-119.

39 Tieman, S.B. and V.B. Hirsch, H., Exposure to lines of only one orientation modifies dendritic morphology of cells in the visual cortex of the cat, J. Comp. Neurol., 211 (1982) 353-362.

40 Tomböl, T., Layer VI cells. In A. Peters and E.G. Jones (Eds.), Cerebral Cortex, Vol. 1, Plenum, New York, 1984, pp. $479-519$.

41 Tsumoto, T., Suda, K. and Sato, H., Postnatal development of corticotectal neurons in the kitten striate cortex: a quantitative study with the horseradish peroxidase technique, J. Comp. Neurol., 219 (1983) 88-99.

42 Valverde, F., Apical dendritic spines of the visual cortex and light deprivation in the mouse, Exp. Brain Res., 3 (1967) 337-352.

43 Valverde, F., Structural changes in the area striata of the mouse after enucleation, Exp. Brain Res., 5 (1968) 274-292.

44 Valverde, F., Aspects of cortical organization related to the geometry of neurons with intracortical axons, $J$. Neurocytol., 5 (1976) 509-529.

45 Van der Loos, H., The 'improperly' oriented pyramidal cell in the cerebral cortex and its possible bearing on problems of neuronal growth and cell orientation, Bull. John Hopkins Hosp., 117 (1965) 228-250.

46 Wahle, P, and Meyer, G., Morphology and quantitative changes of transient NPY-ir neuronal populations during early postnatal development of the cat visual cortex, $J$. Comp. Neurol., 261 (1987) 165-192.

47 Wahle, P., Meyer, G., Wu, J.Y. and Albus, K., Morphology and axon terminal pattern of glutamate decarboxylaseimmunoreactive cell types in the white matter of cat occipital cortex during postnatal development, Dev. Brain Res., 36 (1987) 53-61.

48 Winfield, D.A., The postnatal development of synapses in the different laminae of the visual cortex in the normal kitten and in kitten with eyelid suture, Dev. Brain Res., 9 (1983) 155-169.

49 Wise, S.P., Fleshman, J.W., Jr. and Jones, E.G., Maturation of pyramidal cell form in relation to developing afferent and efferent connections of rat somatic sensory cortex, Neuroscience, 4 (1979) 1275-1297. 